\title{
A rare presentation of ovarian fibrothecoma in a middle age female: case report
}

This article was published in the following Dove Medical Press journal:

International Journal of Women's Health

\author{
Rawan A Obeidat' \\ Abdelwahab J Aleshawi ${ }^{2}$ \\ Hasan A Obeidat ${ }^{2}$ \\ Samir M Al Bashir ${ }^{3}$ \\ 'Department of Obstetrics \& \\ Gynecology, Faculty of Medicine, \\ Jordan University of Science and \\ Technology, Irbid 22 I I 0, Jordan; \\ ${ }^{2}$ Department of General Surgery and \\ Urology, Faculty of Medicine, Jordan \\ University of Science and Technology, \\ Irbid 221 I0, Jordan; ${ }^{3}$ Department of \\ Pathology, Faculty of Medicine, Jordan \\ University of Science and Technology, \\ Irbid 221 I0, Jordan
}

\begin{abstract}
Fibromas/fibrothecomas are considered to be benign ovarian tumors. We describe a rare case of recurrent fibrothecoma with a clinically malignant course. A 42-year-old woman, with no family history of malignancy, operated multiple times for tumor that recurred three times within 4 years despite radical surgical removal. Initially, she presented with $9 \times 7 \times 10 \mathrm{~cm}$ right ovarian mass, frozen section was consistent with fibrothecoma and thus right salpingoophorectomy was performed. At the last two recurrences, she was found to have recurrent multiple abdomino-pelvic fibrothecomas and two long major operations were performed. This malignant behavior of a benign tumor is very rare. Further genetic analysis and immunohistochemistry studies are recommended to be conducted. Furthermore, new modalities of treatment should be considered, eg, high-intensity focused ultrasound and/or hormonal treatment.
\end{abstract}

Keywords: recurrent fibrothecoma, ovarian tumor, radical surgery, sex cord-stromal tumors

\section{Introduction}

Sex cord-stromal tumors are a distinct group of ovarian tumors representing $\sim 7 \%$ of all ovarian neoplasms. ${ }^{1,2}$ Ovarian fibromas/fibrothecomas belong to sex cord-stromal tumors. They are solid benign tumors of the ovary, accounting for $1 \%-4.7 \%$ of all ovarian neoplasms. ${ }^{1-3} \mathrm{We}$ are presenting a rare case of unusual aggressive behavior of fibrothecoma with multiple recurrences in a 42-year-old female.

\section{Case report}

She is a 42-year-old female who is not known to have any medical illness before her complaint. Her parity is 8 , one of her pregnancies is twin. She got her first child at age of 17 and her last one at 28 . Vaginal delivery was the route for all her deliveries. She used nonmedicated inert intrauterine contraceptive device since her last pregnancy until 2009. No family history of malignancy. She was nonsmoker. She did not complain from acne or hirsutism.

She used to have regular cycles; however in 2011, she presented to King Abdullah University Hospital "KAUH" with menorrhagia for 6 months and found to have a $5 \times 6 \mathrm{~cm}$ intramural fibroid. She underwent open myomectomy. The histopathogical study revealed spindle cell proliferation with coagulative necrosis, mild degree of nuclear pleomorphism, and mitotic activity of seven mitotic figures per ten high power fields. The tumor cells were positive for desmin and smooth muscle actin. These findings revealed the presence of smooth muscle tumor of undetermined malignant potential (STUMP). Total abdominal hysterectomy with preservation of both ovaries was performed in 2012. We will discuss each event our patient encountered separately. 


\section{The first event -2014}

While following up the patient; an ultrasound showed right ovarian heterogeneous solid mass. All tumor markers were normal. Further imaging by computed tomography (CT) scan showed a well-defined heterogeneous lesion noted in the right iliac fossa measuring about $9 \times 7 \times 10 \mathrm{~cm}$. At that moment, the patient denied any complaint or symptom. Laparotomy was performed and showed a right ovarian solid mass measuring $10 \times 9 \mathrm{~cm}$ that was attached to the cecum and appendix and was compressing the right ureter and engulfing the right external iliac artery. Frozen section was consistent with fibrothecoma and thus the mass has been resected from both the right ureter and the right external iliac artery and right salpingoophorectomy and appendectomy were performed without any residual disease. The left ovary was preserved as it was normal. On histopathology, the specimen was composed of spindle stromal cells which were randomly distributed in a fascicular fashion. An enough amount of the stromal neoplasm was characterized by theca cells which were oval or rounded with moderate vacuolated cytoplasm. The nuclei were round to oval and exhibit no atypia. The fibromatous component could be seen separating the sheets and nests of theca cells. The mitotic figure was less than four per high power fields. The pathological study was consistent with the diagnosis of fibrothecoma. She was discharged in good circumstances.

\section{The second event -2015}

The patient came back to the clinic complaining of gradual pelvic pain of several months prior to this visit. CT scan revealed a $16.7 \times 11.7 \times 16.7 \mathrm{~cm}$ predominantly cystic mass with heterogeneously enhancing soft tissue components. All tumor markers were normal. She underwent laparotomy in May 2015. This revealed a $6 \times 6 \mathrm{~cm}$ mass arising from the left ovary, large inclusion cyst deep in the pelvis surrounding the rectosigmoid and two solid masses "thecoma" attached to it measuring $4 \times 4 \mathrm{~cm}$ and $5 \times 6 \mathrm{~cm}$. Left salpingoophorectomy and excision of the rectal masses were performed. The tumor was resected completely with no residual disease at the end of the operation. The pathological examination confirmed our suspicion of recurrent fibrothecoma.

\section{The third event - February 2017}

She presented to the emergency department after 2 years with severe right lower limb swelling that involved the whole limb accompanied with right lower quadrant abdominal and right flank pain. Ultrasound demonstrated large mass in the right pelvis. All tumor markers were normal. Estradiol level was $149 \mathrm{pmol} / \mathrm{L}$, and FSH level was $28 \mathrm{IU} / \mathrm{L}$. CT scan showed a large heterogeneous mass occupying the right hemipelvis measuring $13 \times 7.7 \times 17 \mathrm{~cm}$, encasing the right external artery, abutting the right internal iliac artery, and causing compression on the right wall of the urinary bladder and the right ureter resulted in severe right sided hydronephrosis.

Laparotomy was performed in March 2017, this revealed $16 \times 8 \mathrm{~cm}$ solid pelvic mass that extends along the external and internal iliac vessels and right pelvic side wall up to the level of the umbilicus. The mass is densely adherent to the iliac vessels and right ureter causing hydroureter. The mass was resected from the vessels with vascular repair for the veins due to multiple vascular injuries in cooperation with vascular surgeon. The pathological study for the mass revealed another recurrent fibrothecoma. The specimens were reviewed by pathologists in King Hussein Cancer Center "KHCC" for a second opinion and they confirmed our diagnosis.

\section{The fourth event - January 2018}

She presented to our emergency department with bilateral flank pain. Urinary ultrasound showed severe bilateral hydronephrosis. CT scan showed recurrent multiple fibrothecomas (Figure 1B). Bilateral double J stents were inserted. Then, a laparotomy was performed in March 2018 and this showed: extensive adhesions, multiple solid masses including a $6 \times 7 \mathrm{~cm}$ mass just below the right kidney, a $4 \times 4 \mathrm{~cm}$ mass anterior and right to the lower inferior vena cava, a $14 \times 9 \mathrm{~cm}$ mass filling the pouch of Douglas and compressing the rectum, $6 \times 6 \mathrm{~cm}$ and $7 \times 6 \mathrm{~cm}$ solid masses in the lower part of the anterior abdominal wall, a $4 \times 4 \mathrm{~cm}$ mass arising from the right wall of the urinary bladder, and $2 \times 3 \mathrm{~cm}$ mass attached to the mesentery of the small bowel (Figure 1A). The operation took $>9$ hours, and all these masses were excised. The pathological study also revealed a recurrent fibrothecoma. Tumor cells were positive for vimentin, weakly positive for Ki-67, CD10, PR, ER, and negative for cytokeratin and inhibin (Figure $1 \mathrm{C}$ and $\mathrm{D}$ ).

Also, Figure 2 provides a flowchart that summarizes all events the patient encountered.

\section{Discussion}

A fibroma is a benign stromal tumor composed of spindle fibroblastic cells. Ovarian fibroma is the most common benign solid ovarian tumor accounting for $4 \%$ of all ovarian neoplasms. ${ }^{1}$ Thecomas are neoplasm of theca cells. ${ }^{1}$ Thecomas account for about $1 \%$ of ovarian tumors. ${ }^{1}$ Ovarian fibrothecomas are composed of an admixture of fibrous and thecomatous elements. Histologically, these tumors are characterized by the presence of spindle, oval, or round cells forming various amount of collagen and also contain 

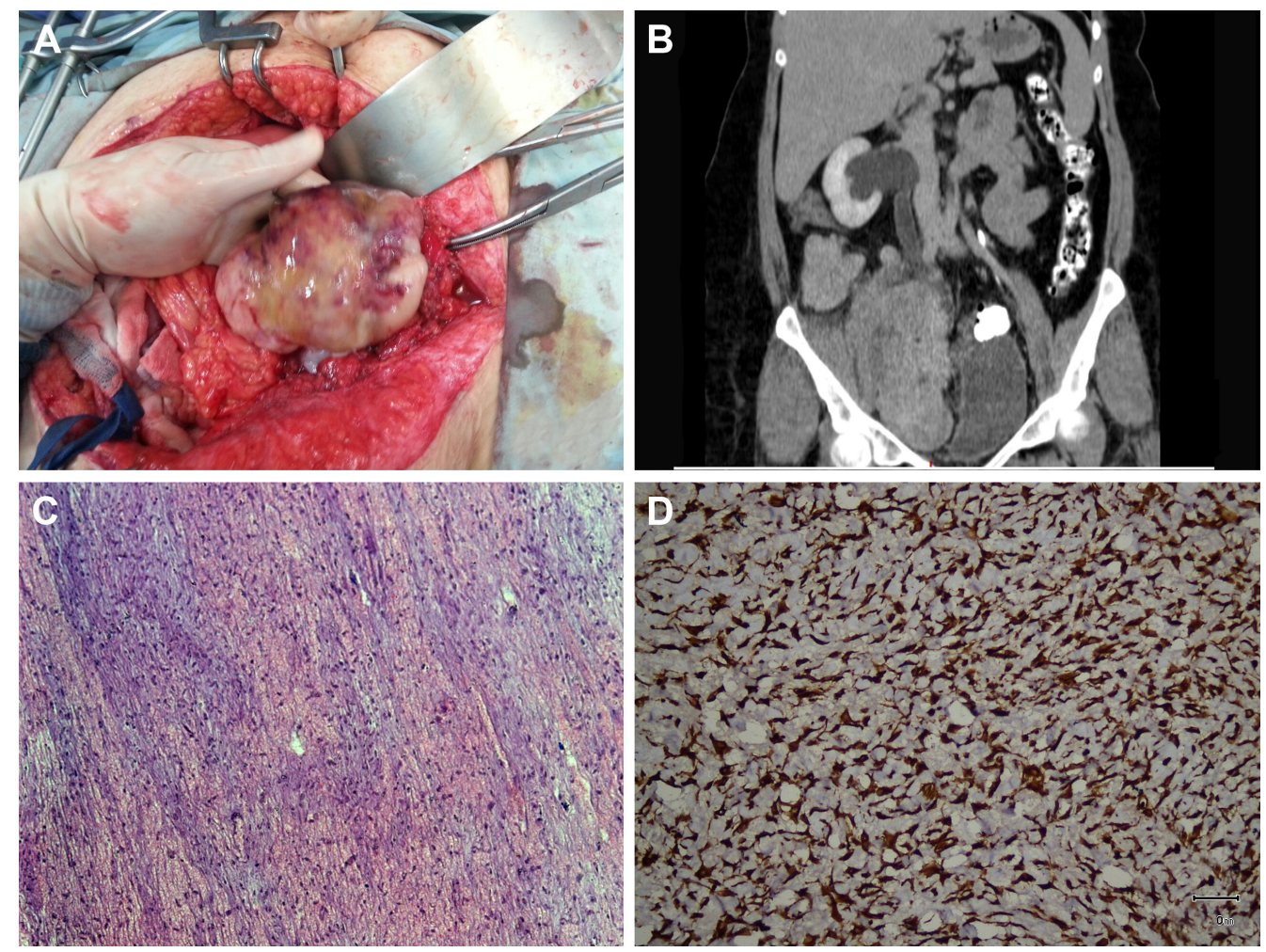

Figure I (A) Intraoperative image of one of the masses. (B) CT scan showed the mass in the right hemipelvis causing severe hydronephrosis. (C) Histopathological study with H\&E stain. Bland looking spindle stromal cells with edema and hyaline bands. Magnification $\times 10$. (D) Immunohistopathological study showing the positive labeling with vimentin. Magnification $\times 20$.

Abbreviation: $\mathrm{CT}$, computed tomography.

a smaller proportion of theca cells. ${ }^{4,5}$ However, there is no universal agreement on which neoplasms should be classified as a fibrothecoma rather than either a fibroma or thecoma. ${ }^{5}$

Fibromas occur most frequently in women in their $50 \mathrm{~s}$ during perimenopause and postmenopause..$^{5}$ They are not hormonally active in most cases. Most of them are unilateral; however, bilateral cases may occur, especially in patients with Gorlin syndrome. In this syndrome, fibromas tend to occur at a younger age, often in children. ${ }^{1,5}$ Like fibromas, thecomas are usually unilateral and occur most commonly in postmenopausal women. In our case, the fibrothecoma was unilateral in a 42-year-old patient.

Fibromas/fibrothecomas most commonly present due to mass effect causing compression on different organs. ${ }^{1,5}$ In some cases, ovarian fibromas can be part of Meigs' syndrome, a triad of ovarian fibroma, ascites, and pleural effusion. Torsion occurs in $8 \%$ of the patients. ${ }^{6}$ Patients may also present with endocrine manifestations such as estrogenic or less commonly androgenic stimulation related to hormonally active thecoma elements. ${ }^{1,5}$ Serum CA-125 levels are usually found in normal range in ovarian fibroma/fibrothecoma; ${ }^{5}$ however, elevated levels have been reported in patients presented with Meigs' syndrome. ${ }^{7}$ In our case, the patient was initially asymptomatic; however, she presented with gradual pelvic pain in her first relapse. In her second relapse, she had right leg swelling, right lower quadrant abdominal, and right flank pain. Bilateral flank pain was the main complaint in her third relapse. She denied endocrine manifestations such as acne or hirsutism. Ca125 level was in normal range.

The modality of treatment could be tumor excision alone, uni- or bilateral salpingooophorectomy with or without hysterectomy depending on the patient status and the aggressiveness of the tumor. ${ }^{3}$ In our case, right salpingoophorectomy and appendectomy were initially performed. Later, left salpingoophorectomy and rectal mass excision were performed. After that, the patient had multiple recurrences for which two long major operations were performed to remove the multiple masses.

What is unique about this case is the clinical malignant course of this benign tumor. Differential diagnosis includes fibrosarcoma or recurrent STUMP. The pathology has been reviewed by expert pathologists, and the diagnosis of benign fibrothecomas has been confirmed. Fibrosarcomas are very rare ovarian sarcomas. Histologically, they are characterized by marked cellular activity and nuclear atypia, and four or more mitotic figures per ten high power fields. The aggressiveness of this tumor correlates with the number of mitosis and the degree of anaplasia. 


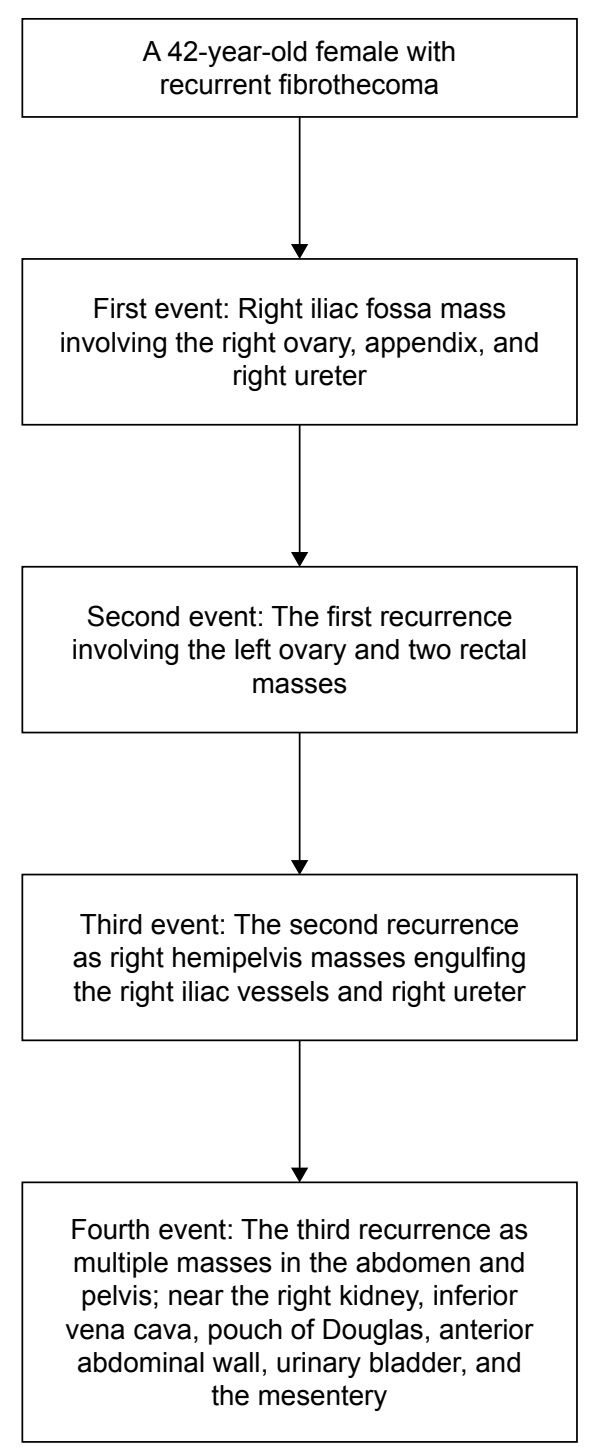

Figure 2 Flowchart summarizes all events the patient encountered.

The term STUMPs indicate a group of uterine smooth muscle tumors that have some characteristics of leiomyosarcomas but do not meet full diagnostic criteria. The Stanford diagnostic criteria for leiomyosarcoma include at least two of the following: diffuse moderate to severe atypia, a mitotic count of at least ten mitotic figures per ten high power fields and tumor necrosis. ${ }^{8}$ STUMPs are rare and we have limited data on their clinical behavior. Recurrence is estimated between $8.7 \%$ and $11 \%{ }^{9}$ These tumors are concerning in terms of progression or missed diagnosis of leiomyosarcomas.

The aggressive behavior of this benign fibrothecoma is very rare. Further genetic analysis and immunohistochemistry studies are recommended to be conducted to identify the cohort of patients at risk of recurrence. In addition, the tumor recurred within short intervals despite multiple radical surgeries and thus we should think of other less morbid alternatives, eg, high-intensity focused ultrasound and/or hormonal treatment.

\section{Ethics and patient consent}

The patient has provided written informed consent for the case details and images to be published. Institutional approval was not required.

\section{Disclosure}

The authors report no conflicts of interest in this work.

\section{References}

1. Kurman RJ, Carcangiu ML, Herrington CS, Young RH. WHO Classification of Tumours of Female Reproductive Organs. 4th edn. IARC WHO Classification of Tumours. No. 6. IARC: Lyon; 2014.

2. Horta M, Cunha TM. Sex cord-stromal tumors of the ovary: a comprehensive review and update for radiologists. Diagn Interv Radiol. 2015; 21(4):277-286

3. Cho YJ, Lee HS, Kim JM, Joo KY, Kim ML. Clinical characteristics and surgical management options for ovarian fibroma/fibrothecoma: a study of 97 cases. Gynecol Obstet Invest. 2013;76(3):182-187.

4. Troiano RN, Lazzarini KM, Scoutt LM, Lange RC, Flynn SD, McCarthy S. Fibroma and fibrothecoma of the ovary: MR imaging findings. Radiology. 1997;204(3):795-798.

5. Numanoglu C, Kuru O, Sakinci M, Akbayır O, Ulker V. Ovarian fibroma/ fibrothecoma: retrospective cohort study shows limited value of risk of malignancy index score. Aust N Z J Obstet Gynaecol. 2013;53(3): 287-292.

6. Bazot M, Ghossain MA, Buy JN, et al. Fibrothecomas of the ovary: CT and US findings. J Comput Assist Tomogr. 1993;17(5):754-759.

7. Angeles RM, Salem FL, Sirota RL. A right ovarian mass in a 71-yearold woman with ascites and elevated CA 125 level. Fibrothecoma of the right ovary. Arch Pathol Lab Med. 2005;129(5):701-702.

8. Bell SW, Kempson RL, Hendrickson MR. Problematic uterine smooth muscle neoplasms. A clinicopathologic study of 213 cases. Am J Surg Pathol. 1994;18(6):535-558.

9. Ip PP, Cheung AN, Clement PB. Uterine smooth muscle tumors of uncertain malignant potential (STUMP): a clinicopathologic analysis of 16 cases. Am J Surg Pathol. 2009;33(7):992-1005.

International Journal of Women's Health

\section{Publish your work in this journal}

The International Journal of Women's Health is an international, peerreviewed open-access journal publishing original research, reports, editorials, reviews and commentaries on all aspects of women's healthcare including gynecology, obstetrics, and breast cancer. The manuscript management system is completely online and includes

a very quick and fair peer-review system, which is all easy to use Visit http://www.dovepress.com/testimonials.php to read real quotes from published authors.

\section{Dovepress}

Submit your manuscript here: http://www.dovepress.com/international-journal-of-womens-health-journal 